\title{
Article \\ Study on the Seismic Performance of Prefabricated Single-Segment Steel Jacket Bridge Piers
}

\author{
Baodong Deng ${ }^{1}$, Yanmin Jia ${ }^{1, *}$ and Dongwei Liang ${ }^{2}$ \\ 1 School of Civil Engineering, Northeast Forestry University, Harbin 150040, China; 2019110585@nefu.edu.cn \\ 2 MCC Capital Engineering \& Research Incorporation Limited, Beijing 100176, China; \\ liangdongwei2002@163.com \\ * Correspondence: jiayanmin@nefu.edu.cn
}

Citation: Deng, B.; Jia, Y.; Liang, D. Study on the Seismic Performance of Prefabricated Single-Segment Steel Jacket Bridge Piers. Symmetry 2021, 13, 2312. https://doi.org/ $10.3390 /$ sym 13122312

Academic Editor: Chiara Bedon

Received: 6 November 2021

Accepted: 30 November 2021

Published: 3 December 2021

Publisher's Note: MDPI stays neutral with regard to jurisdictional claims in published maps and institutional affiliations.

Copyright: (c) 2021 by the authors. Licensee MDPI, Basel, Switzerland. This article is an open access article distributed under the terms and conditions of the Creative Commons Attribution (CC BY) license (https:// creativecommons.org/licenses/by/ $4.0 /)$.

\begin{abstract}
To study the seismic performance of prefabricated single-segment steel jacket piers connected by grouting sleeves, two scaled symmetrical pier models with different anchorage lengths of the longitudinal reinforcement in the grouting sleeves and a comparative symmetrical cast-in-place (CIP) model were designed. OpenSees finite element models were established and shaking table tests were carried out on the three scaled pier models. The seismic response of each pier was compared and analyzed. Results showed the stiffness of the two prefabricated piers was greater than that of the CIP pier, and other seismic responses were less than those of the CIP piers, The dynamic responses of the two prefabricated bridge models were similar and changing the anchorage length of the reinforcement in the grouting sleeve had little effect on the seismic performance of the prefabricated pier. The simulation results were in good agreement with the experimental results. In the parameter analysis, the counterweight of the pier top had the greatest influence on the seismic performance of the prefabricated pier. The anchorage length of the longitudinal reinforcement in the grouting sleeve could be 6-14 times the diameter of the longitudinal reinforcement. Moreover, the seismic performance was found to be optimal when the thickness of the steel jacket was 5-7 mm.
\end{abstract}

Keywords: prefabricated pier; grouting sleeve; steel jacket; shaking table test; seismic performance; OpenSees

\section{Introduction}

In recent years, with the popularization of prefabricated structures, accelerated bridge construction $(\mathrm{ABC})$ technology has been adopted for increasingly more bridges [1-4]. Compared with traditional cast-in-place (CIP) piers, prefabricated piers have the advantages of reduced traffic congestion [5], a fast construction speed [6], and high construction quality and safety $[7,8]$. Therefore, the seismic performance of prefabricated piers has become a research hotspot in recent years.

Many scholars have previously carried out seismic tests and research on piers with steel jackets and prefabricated piers connected by grouting sleeves $[9,10]$. For instance, Deng et al. [11] reinforced the pier with initial damage with a steel jacket and carried out quasi-static tests, followed by using OpenSees to establish the fiber model. The results show that the seismic performance of the steel jacket reinforced pier is improved significantly, and the simulation results agree with the test results. Ding [12] reinforced 23 bridge piers by wrapping carbon fiber, outer concrete, and outer steel jacket, and carried out pseudo-static test. The results show that the steel jacket is the best in improving the bearing capacity and ductility. Fan [13] applied steel jacket to bridge pier and carried out pseudo-static test. The results show that although the energy dissipation effect of steel jackets is slight, the ductility and bearing capacity of bridge piers can be significantly improved. Huang et al. $[14,15]$ used OpenSees finite element software to perform finite element analyses on piers reinforced with steel jackets, and the results showed that the reinforced piers exhibited a significantly increased bearing capacity and effectively reduced 
displacement and residual deformation of the pier top. Wang et al. [16] used OpenSees to conduct numerical simulation research on prefabricated segmental bridge piers connected with grouting sleeves. The results showed that the overall dynamic response of the prefabricated bridge piers was similar to that of CIP bridge piers. Moreover, the ultimate lateral force was slightly larger than that of the CIP bridge piers, while the displacement and ductility were less than those of the CIP bridge piers. Hewes [17] used steel jackets to constrain plain concrete in the potential plastic hinge area of multi-segment prefabricated piers. Via pseudo-static tests, it was proven that the structure constrained by steel jackets exhibited better integrity and energy dissipation capacity, and the unconstrained section was found to be the weakest area of the entire pier. Bertha et al. [18] Studied the influence of steel jackets on the seismic performance of bridges by inputting 10 seismic waves into the structure through numerical simulation, Results show that the confining effect provided by the steel jackets substantially improves the seismic performance of the bridges piers. Zhang et al. [19] Adopted a composite structure combined steel jacket and prestressed steel hoop to reinforce the damaged column after the concrete column was destroyed by the pseudo-static test. The results showed that the repair method was proved to be effective in restoring the structural behavior of the damaged columns to prevent bridge collapse. Chou et al. [20] conducted a pseudo-static test of two multi-segment steel jacket prefabricated bridge piers with penetrating prestressed reinforcement. The results showed that the flexural bearing capacity and energy dissipation characteristics of the structure were enhanced, and the residual displacement was effectively controlled. Ameli et al. [21] conducted a pseudo-static test on prefabricated bridge piers installed with grouting sleeves in the plastic hinge areas and caps, respectively, and the test results showed that the former was more stable after reinforcement yielding, while the latter had better durability after reinforcement yielding. Guo et al. [22] conducted a shaking table test analysis of piers connected by grouting sleeves under high-intensity earthquake conditions, and the results revealed that the seismic performance of the prefabricated piers connected by grouting sleeves was better than that of CIP piers.

There currently exist few research results on the effects of the anchorage length of the reinforcement in the grouting sleeve and the steel jacket on the seismic performance of prefabricated piers, and previous research has mainly adopted pseudo-static tests as the experimental method. However, pseudo-static tests cannot accurately reflect the dynamic response of a structure under the action of real ground motion $[23,24]$. In contrast, the seismic wave input to the table surface in the shaking table test can truly restore the dynamic response of the structure under the action of an earthquake, which effectively overcomes the deficiencies of the pseudo-static test.

According to the same set of tests [25], it has been proved that the prefabricated singlesegment bridge pier connected with a grouting sleeve has better seismic performance than the CIP bridge pier. In order to better improve the seismic response of single-segment prefabricated pier, steel jackets were installed in the plastic hinge area of the pier bottom bridge. A new type of single-segment prefabricated bridge pier structure that combines a steel jacket and a grouting sleeve is proposed. The grouting sleeve is used to connect single segments, and the potential plastic hinge area at the bottom of the pier is wrapped with a steel jacket. Shaking table tests were carried out to study the effects of different anchorage lengths on the seismic performance of the new structure.

\section{Shaking Table Test}

\subsection{Similarity Relationship}

This experiment took a prefabricated bridge pier as the prototype, and the geometric scale ratio was determined as 1:4. The similarity coefficients of the main physical quantities between the model and the prototype according to the uniform similarity law [26] are reported in Table 1. 
Table 1. Similarity coefficient.

\begin{tabular}{ccc}
\hline Physical Quantity & Similarity Relation & Similarity Coefficient \\
\hline Length & $l_{r}$ & 0.25 \\
Area & $S_{r}=l_{r}^{2}$ & 0.0625 \\
Elastic modulus & $E_{r}$ & 0.689 \\
Equivalent density & $\bar{\rho}=m_{m}+m_{a}+m_{o m} / l_{r}^{3}\left(m_{p}+m_{o p}\right)$ & 1.409 \\
Acceleration & $a_{r}=E_{r} / l_{r} \bar{\rho}_{r}$ & 1.957 \\
Mass & $m_{r}=\bar{\rho}_{r} l_{r}^{3}$ & 0.022 \\
Time & $t_{r}=l_{r}\left(\bar{\rho}_{r} / E_{r}\right)^{0.5}$ & 0.358 \\
Velocity & $v_{r}=\left(E_{r} / \bar{\rho}_{r}\right)^{0.5}$ & 0.699 \\
Frequency & $\omega_{r}=\left(E_{r} / \bar{\rho}_{r}\right)^{0.5} / l_{r}$ & 2.798 \\
Stress & $\sigma_{r}=E_{r}$ & 0.689 \\
Strain & $\varepsilon_{r}=1$ & 1 \\
\hline
\end{tabular}

\subsection{Model Fabrication and Measuring Point Arrangement}

Three specimens were designed and fabricated, numbered CIP, SJ1, and SJ2 respectively. The three piers were made of the same material, C20 concrete, HRB400 longitudinal reinforcement, HPB300 spiral reinforcement, and Q235 steel jacket. Integral casting was adopted for CIP. SJ1 and SJ2 were prefabricated, the cap and pier were connected by 6 grouting sleeves and high-strength setting grout. The anchorage length of reinforcement in the grouting sleeves is 10 times and 8 times of steel bar diameter respectively [27]. High-strength grouting materials were poured into the grouting sleeves. The steel jacket was using epoxy resin attached to the pier which height of $40 \mathrm{~cm}$. The counterweight at the pier top was $400 \mathrm{~kg}$. The Schematic diagram of the pier is presented in Figure 1.

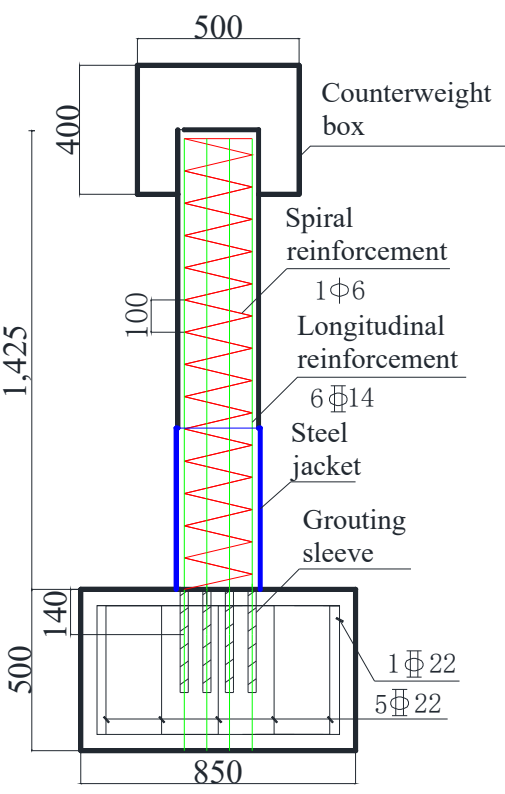

(a)

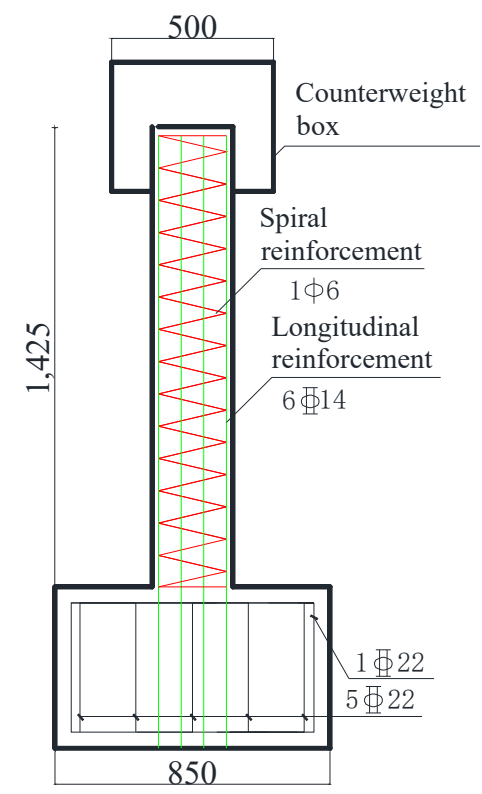

(b)

Figure 1. Schematic diagram of pier (mm); (a) Reinforcement drawing of assembly pier (mm); (b) Reinforcement drawing of CIP pier (mm).

Three groups of acceleration sensors and displacement sensors are arranged in the $X$ and $Y$ directions of the upper, middle, and lower parts of the pier, and four groups of reinforcement and concrete strain gauges are arranged in the potentially damaged plastic hinge positions of the pier. The layout of measuring points is shown in Figure 2. 


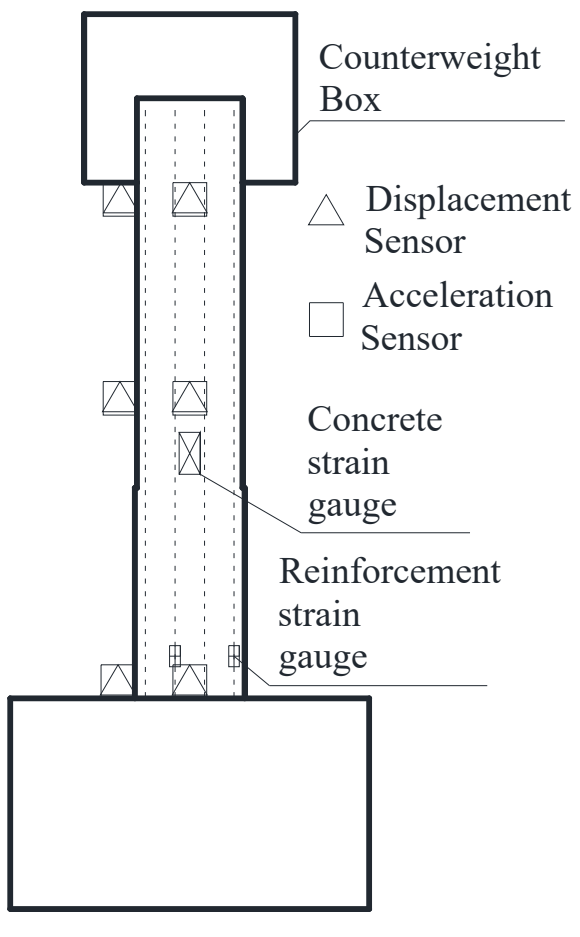

(a)

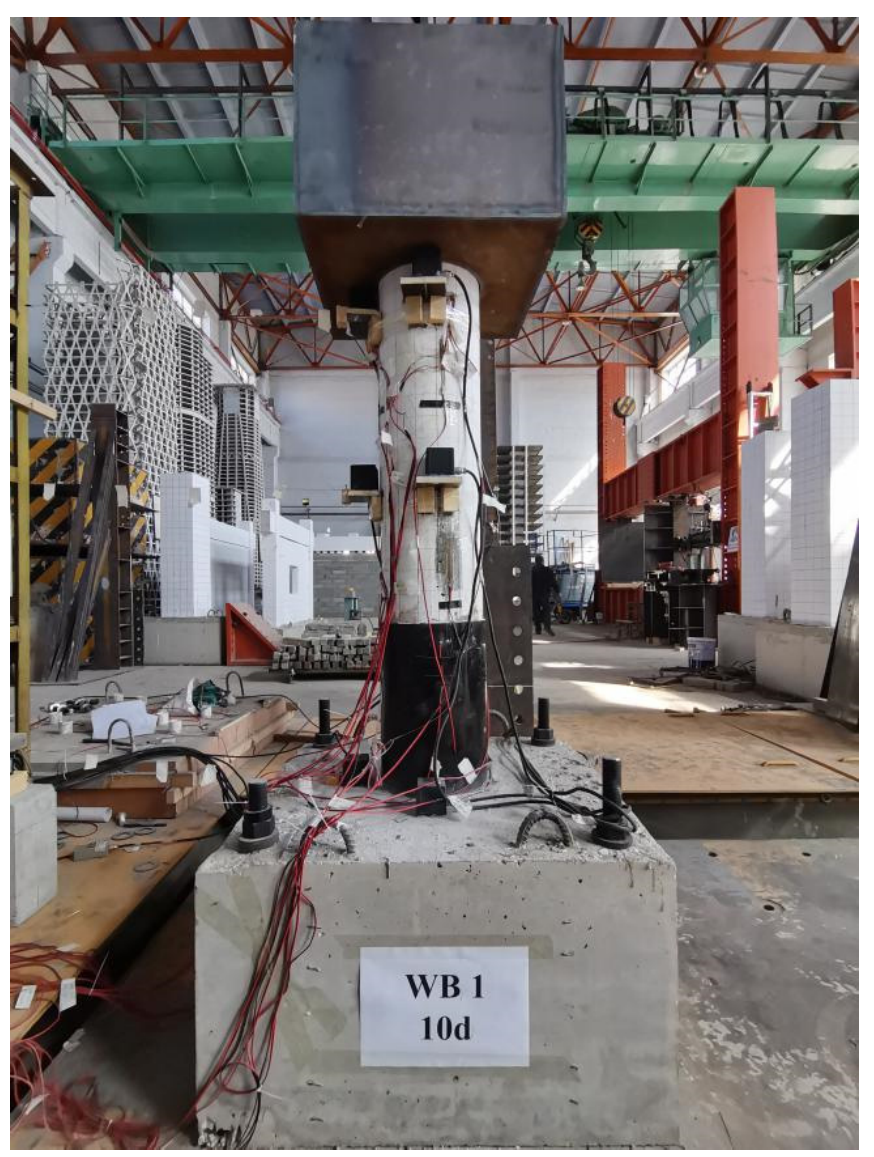

(b)

Figure 2. Layout of measuring points. (a) Schematic diagram of measuring point; (b) Test photo.

\subsection{Seismic Wave Selection and Load Condition}

According to the site conditions of the prototype and the actual test conditions, three seismic waves, El-Centro, Taft111, and Taft21, were selected. As shown in Figure 3, when PGA is $0.274 \mathrm{~g}$ and $0.783 \mathrm{~g}$, the acceleration response spectra of the three seismic waves were in good agreement with the response spectra designed in the specification, which proves the effectiveness of the selected waves.

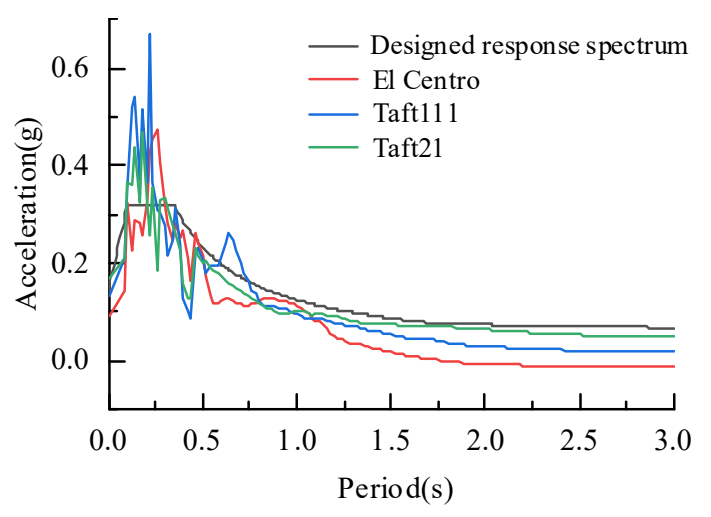

(a)

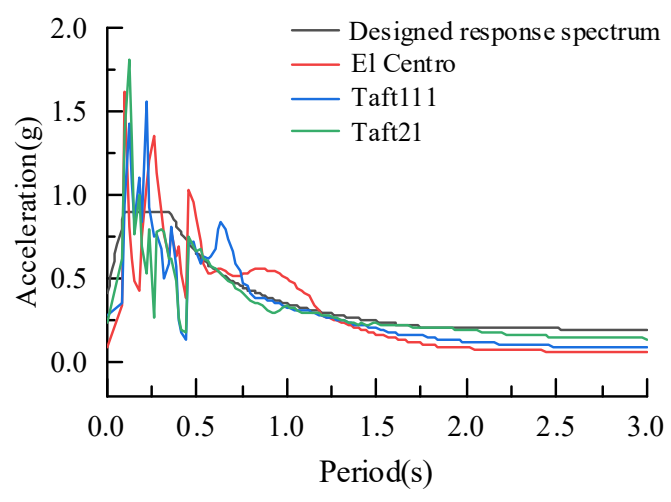

(b)

Figure 3. Comparison between the different ground motion acceleration response spectra and code design spectra: (a) under PGA $0.274 \mathrm{~g}$; (b) under PGA $0.783 \mathrm{~g}$. 
According to specifications [28,29], under each level of PGA, the ratio of $X$ to $Y$ direction in the first two working conditions is 1:0.85, and that in the third working condition is 1:0.88. The seismic wave duration is compressed to $35.8 \%$ of the original wave duration. Loading conditions are shown in Table 2.

Table 2. Loading condition table.

\begin{tabular}{|c|c|c|c|c|c|c|c|}
\hline Loading Condition & Seismic Wave & X-Direction (g) & Y-Direction (g) & Loading Condition & Seismic Wave & X-Direction (g) & Y-Direction (g) \\
\hline \multirow{2}{*}{1} & $\begin{array}{l}\text { EL-Centro } \\
\text { Taft } 111\end{array}$ & 0.137 & 0.116 & \multirow{2}{*}{5} & $\begin{array}{l}\text { EL-Centro } \\
\text { Taft } 111\end{array}$ & 0.55 & 0.47 \\
\hline & Taft111/Taft21 & 0.137 & 0.121 & & Taft111/Taft21 & 0.55 & 0.485 \\
\hline \multirow[t]{2}{*}{2} & $\begin{array}{l}\text { EL-Centro } \\
\text { Taft } 111\end{array}$ & 0.274 & 0.233 & \multirow[t]{2}{*}{6} & $\begin{array}{l}\text { EL-Centro } \\
\text { Taft } 111\end{array}$ & 0.65 & 0.55 \\
\hline & Taft111/Taft21 & 0.274 & 0.241 & & Taft111/Taft21 & 0.65 & 0.573 \\
\hline \multirow[t]{2}{*}{3} & $\begin{array}{l}\text { EL-Centro } \\
\text { Taft } 111\end{array}$ & 0.391 & 0.332 & \multirow[t]{2}{*}{7} & $\begin{array}{c}\text { EL-Centro } \\
\text { Taft } 111\end{array}$ & 0.783 & 0.666 \\
\hline & Taft111/Taft21 & 0.391 & 0.345 & & Taft111/Taft21 & 0.783 & 0.69 \\
\hline \multirow[t]{2}{*}{4} & $\begin{array}{l}\text { EL-Centro } \\
\text { Taft } 111\end{array}$ & 0.431 & 0.366 & \multirow[t]{2}{*}{8} & $\begin{array}{c}\text { EL-Centro } \\
\text { Taft } 111\end{array}$ & 0.9 & 0.77 \\
\hline & Taft111/Taft21 & 0.431 & 0.38 & & Taft111/Taft21 & 0.9 & 0.793 \\
\hline
\end{tabular}

\section{Seismic Response Analysis and Finite Element Simulation Comparison}

\subsection{Establishment of OpenSees Finite Element Model}

The Concrete 02 material model in OpenSees was adopted for the constitutive relationship of concrete, where fpc is the peak compressive strength of concrete after 28 days of test curing, epsco is the corresponding peak strain, fpcu and epscu are the ultimate compressive strength and ultimate strain, respectively, and lambda is the ratio of the unloading stiffness to the initial elastic modulus of concrete when the ultimate strain is reached. For the core concrete constrained by spiral stirrups, the parameter values were calculated using the Mander model [30] in consideration of the strong confinement effect of the spiral stirrups on the concrete. For the concrete in the unreinforced area, the parameter values were calculated using the Kent-Park model.

The Steel 02 constitutive model in OpenSees was used for both the longitudinal steel bars and the steel jacket, for which the uniaxially isotropically strengthened GiuffreMenegotto-Pinto constitutive model was adopted [31]; this is a bilinear follow-up strengthening model that can better reflect the Bauschinger effect. In the model, Fy is the yield strength of longitudinal bars, E0 is the modulus of elasticity, and b is the hardening rate of the steel bars, which is considered as 0.01 . In addition, the three parameters R0, CR1, and CR2 can fine-tune the constitutive relationship of Steel 02. In the model, R0 was set to 18, CR1 was set to 0.925 , and CR2 was set to 0.15 . The constitutive model is shown in Figure 4 .

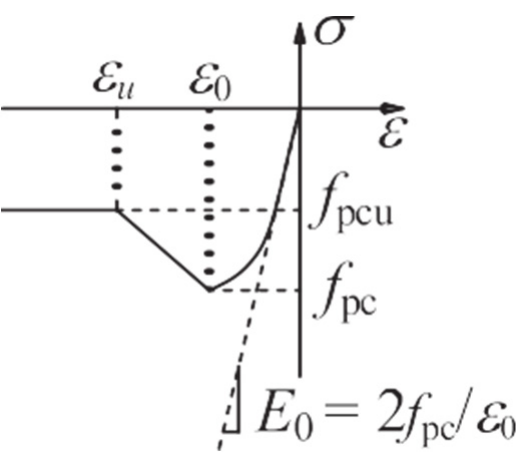

(a)

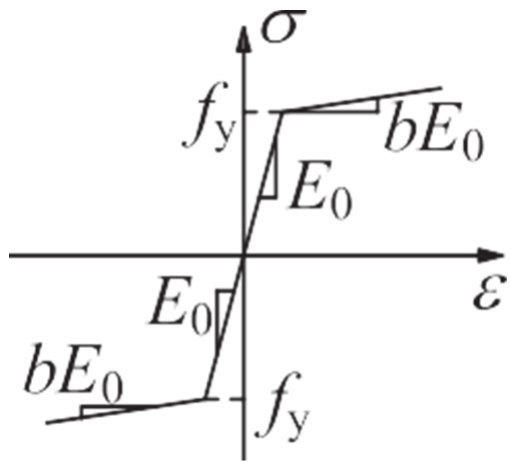

(b)

Figure 4. Constitutive model: (a) concrete model; (b) reinforcement and steel jacket model. 
The Force-Beam Column element and the rigid beam in OpenSees were used to simulate the mechanical performance of the grouting sleeve, and the anchorage length was achieved by changing the length of the element. The joint between the cap and the pier was simulated by an elastic section and, the top of the grouting sleeve and the bottom of the pier were connected by six zero-length elements. For high-strength grout materials, UniaxialMaterial Elastic was used in the DIR-1,2,6 directions of the zero-length element, and Elastic-No Tension (ENT) material was used in the DIR-3 direction. The measured value of high-strength grouting material was taken.

The steel jacket section is divided into one part in the ring direction and 18 parts in the radial direction. The section without the steel jacket is divided into five parts in the ring direction and 18 parts in the radial direction. Section division is shown in Figure 5.

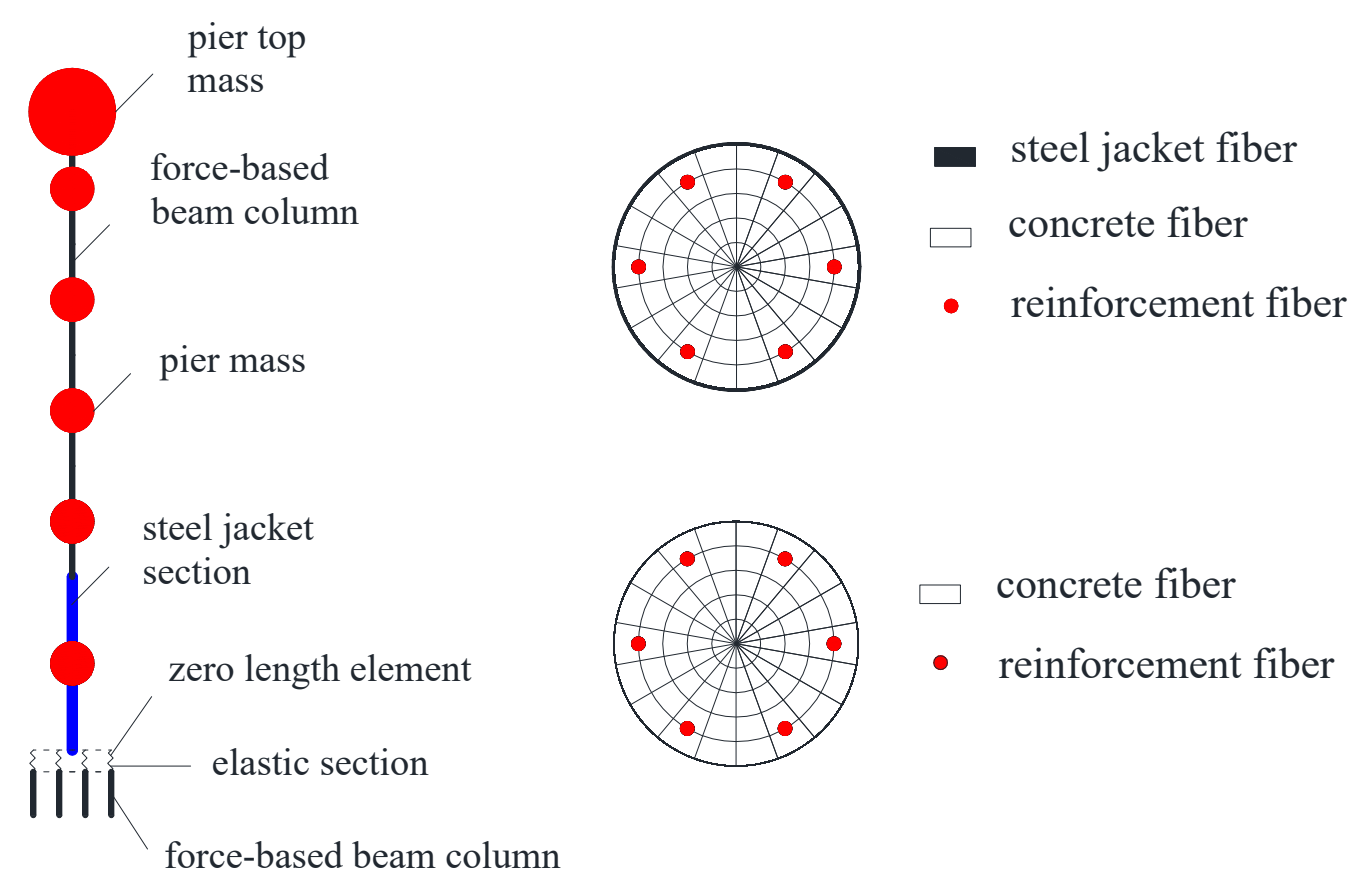

(a)

(b)

Figure 5. (a) Schematic diagram of the model; (b) section division.

The nonlinear beam-column element based on the flexibility method was used in the numerical model of the prefabricated piers to simulate the elastic-plastic bending deformation of the piers. A concentrated mass was applied to the top of the numerical model of the piers to simulate the weight of the bridge superstructure, and the damping of the model was Rayleigh damping.

The dynamic time-history analysis of the piers was conducted by inputting different scale factors to achieve the gradual increase of the PGA, and finally using the Recorder command to output the pier response under earthquake conditions.

\subsection{Recurrence of Seismic Waves}

Taking the three input X-direction seismic waves with a PGA of $0.55 \mathrm{~g}$ as an example, Figure 6 presents the comparison between the theoretical and actual values of the three input seismic waves. The error between the theoretical and actual values was found to be small, the wave forms of the acceleration time-history curves were basically the same, and the input seismic waves were well repeated, which proves that the loading process was effective. 


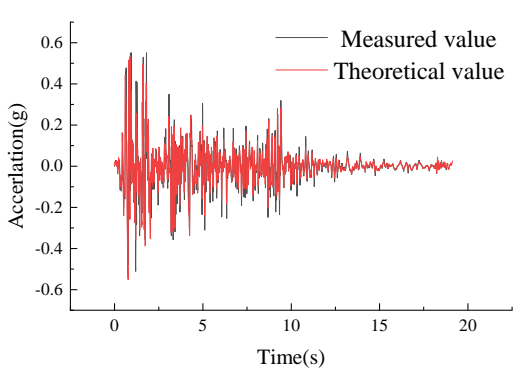

(a)

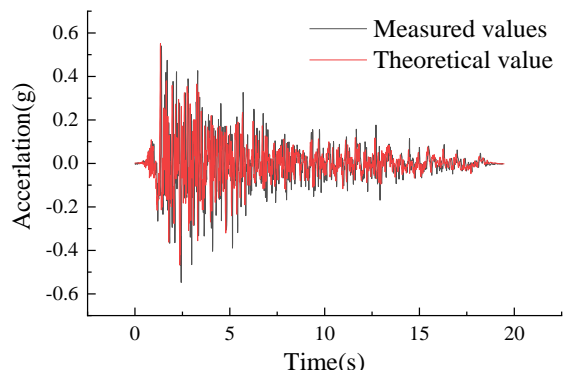

(b)

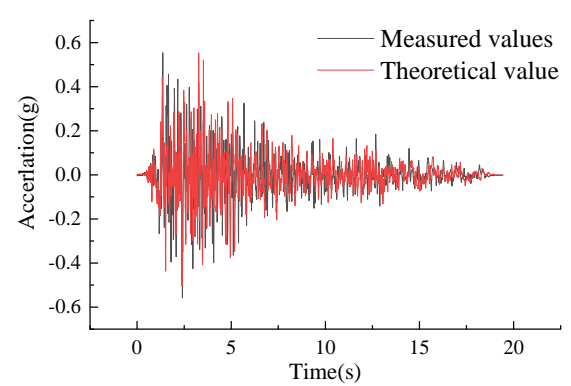

(c)

Figure 6. Comparison of acceleration time history: (a) El-Centro; (b) Taft21; (c) Taft111.

\subsection{Natural Frequency}

At the end of each stage of loading, $0.05 \mathrm{~g}$ of the white noise input on the table was swept. After frequency sweeping, a fast Fourier transform (FFT) was performed on the time-history curve of the acceleration of the pier top at each stage of loading to obtain the first-order natural vibration frequency after loading. The first-order natural vibration frequencies of the three piers before loading were respectively 13.86, 13.66, and $9.59 \mathrm{~Hz}$. Table 3 reports the first-order natural vibration frequency and the rate of stiffness decrease under different loading conditions, as well as the calculation results of the OpenSees finite element analysis.

Table 3. Test natural frequency.

\begin{tabular}{cccccc}
\hline & SJ1 (HZ) & SJ2 (HZ) & CIP (HZ) & SJ1 Simulation (HZ) & SJ2 Simulation (HZ) \\
\hline Initial frequency & 13.66 & 13.86 & 9.59 & 12.06 & 12.05 \\
$0.137 \mathrm{~g}$ & 13.41 & 12.33 & 9.03 & 11.74 & 11.87 \\
$0.274 \mathrm{~g}$ & 12.54 & 12.46 & 8.81 & 11.53 & 11.73 \\
$0.391 \mathrm{~g}$ & 12.68 & 12.5 & 8.44 & 11.47 & 11.51 \\
$0.431 \mathrm{~g}$ & 12.42 & 12.08 & 8.25 & 11.21 & 11.45 \\
$0.55 \mathrm{~g}$ & 11.23 & 10.94 & 8.18 & 11.09 & 11.2 \\
$0.65 \mathrm{~g}$ & 10.86 & 10.76 & 7.47 & 10.78 & 11.08 \\
$0.783 \mathrm{~g}$ & 10.84 & 10.78 & 7.27 & 10.55 & 10.76 \\
$0.9 \mathrm{~g}$ & 10.34 & 10.21 & 6.89 & 12.5 & 10.53 \\
Decrease rate/\% & 24.3 & 26.33 & 28.46 & & \\
\hline
\end{tabular}

It can be seen from Table 3 that the rates of stiffness decline of the two prefabricated piers were less than that of the CIP pier. Moreover, the natural vibration frequencies of the three piers all decreased with the increase of the PGA. This is because the piers were gradually damaged with the increase of the PGA, resulting in a longer period and a decrease in stiffness. The natural vibration frequency of pier SJ1 was slightly higher than that of pier SJ2, which is because the anchorage length of pier SJ2 was slightly less than that of pier SJ1. The final natural frequency after the test is close to. Until the end of all loading conditions, the natural vibration frequency of the two steel jacket prefabricated piers was still significantly greater than that of the CIP pier. Changing the anchorage length of the reinforcement in the grouting sleeve was found to have little influence on the natural vibration frequency and stiffness. According to the OpenSees finite element simulation results, the natural vibration frequency was determined, and the simulated stiffness values were greater than those in the experiment; this was due to the existence of some subtle defects in the fabrication process of the components as compared to the ideal finite element calculation.

\subsection{Acceleration Response}

Figure 7 exhibits the peak acceleration of the pier tops in the X-direction with the increase of the PGA increase under different seismic waves, as well as the finite element 
simulation results. The peak acceleration of the pier tops in the X-direction was found to gradually increase with the increase of the PGA. When the PGA was less than $0.391 \mathrm{~g}$, there was little difference between the peak accelerations of the pier tops of the three piers. When the PGA was greater than $0.391 \mathrm{~g}$, the peak accelerations of the pier tops of piers SJ1 and SJ2 were less than that of pier CIP. When the PGA was greater than $0.391 \mathrm{~g}$, the peak accelerations of the pier tops of piers SJ1 and SJ2 were less than that of pier CIP. When the PGA was less than $0.431 \mathrm{~g}$, the peak acceleration of pier SJ1 was slightly less than that of pier SJ2. When the PGA was greater than $0.431 \mathrm{~g}$, the peak acceleration of pier SJ1 was slightly greater than that of pier SJ2. It can be seen that the overall acceleration response of the two prefabricated piers exhibited little difference, and the peak acceleration of the three piers increased linearly overall. The three piers experienced the maximum peak acceleration under the action of the bidirectional Taft seismic wave, and the minimum acceleration response occurred under the action of the El-Centro wave. The simulation results of piers SJ1 and SJ2 were similar, which verifies the correctness of the finite element model. It can be concluded from the preceding analysis that the acceleration response of the single-segment prefabricated pier with a steel jacket was less than that of the CIP pier under different seismic waves, which is because the transverse constraint of the steel jacket enhanced the transverse stiffness of the prefabricated pier. However, changing the anchorage length of the reinforcement in the grouting sleeve was found to have little effect on the peak acceleration response within a certain range.

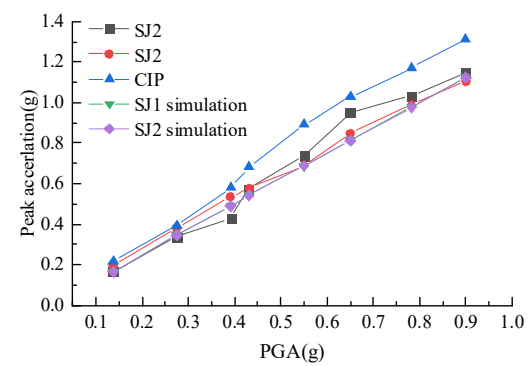

(a)

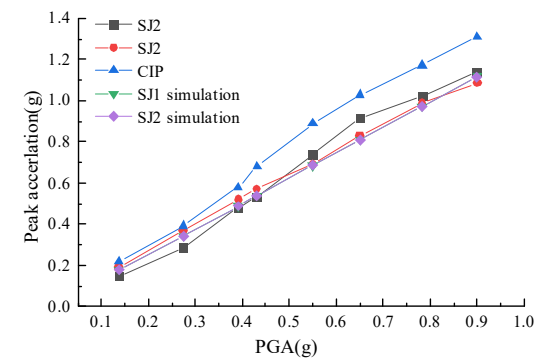

(b)

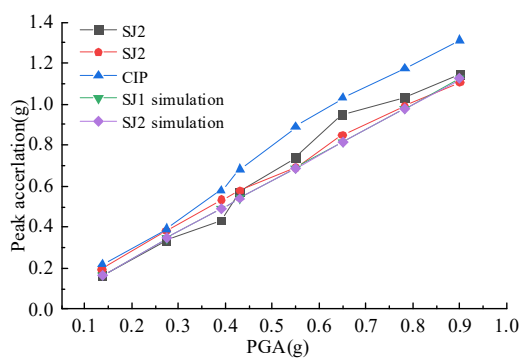

(c)

Figure 7. Acceleration time-history curve of pier top in X direction: (a) El-Centro; (b) Taft111; (c) Taft111(X) and Taft21(Y).

\subsection{Displacement Response}

Figure 8 displays the maximum relative peak displacement values of the three piers in the X-direction and the OpenSees calculation results under the action of different levels of seismic waves. As the PGA gradually increased, the relative peak displacement value of pier SJ2 was only slightly larger than that of pier SJ1, and both exhibited a linear increasing trend. The simulation results of piers SJ1 and SJ2 were also similar. Thus, changing the anchorage length of the reinforcement in the grouting sleeve was found to have little influence on the displacement response of the prefabricated piers within a certain range. Compared with the CIP pier, the relative peak displacement values of the prefabricated piers were significantly lower, which was due to the lateral constraint of the steel jacket; this increased the stiffness of the prefabricated piers, which imposed an obvious restriction on the lateral displacement.

To more clearly express the limiting effect of the steel jacket on pier displacement, the influence rate $i$ of pier displacement is defined as follows:

$$
i=\frac{\left(D_{1}-D_{2}\right)}{D_{1}}
$$

where $D_{1}$ is the peak value of the maximum relative displacement of the pier top of CIP pier under a certain working condition, and $D_{2}$ is the peak value of the maximum relative displacement of the pier tops of piers SJ1 and SJ2 under a certain working condition. 
Tables 4 and 5 respectively report the influence rates of piers SJ1 and SJ2 under the action of the three types of seismic waves at PGA values of $0.274,0.55$, and $0.783 \mathrm{~g}$.

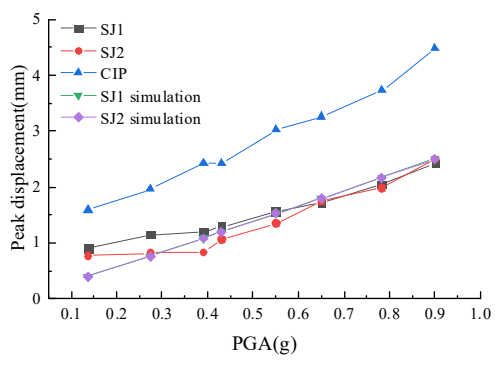

(a)

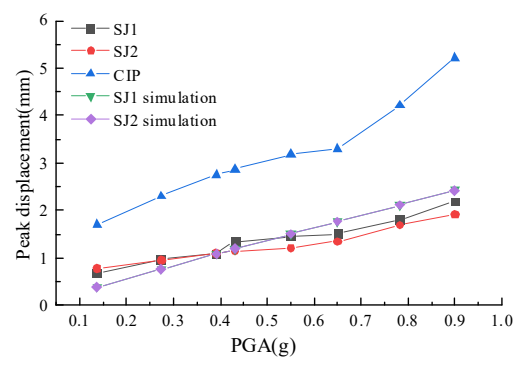

(b)

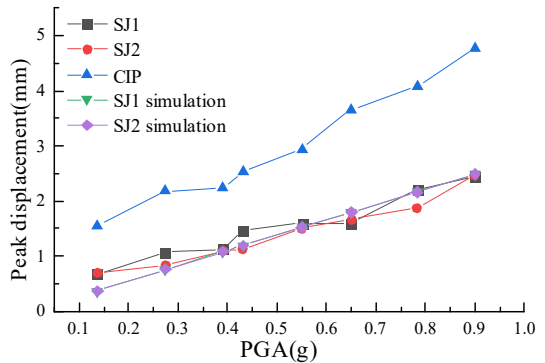

(c)

Figure 8. Peak relative displacement of pier top under different seismic wave: (a) El-Centro; (b) Taft111; (c) Taft111(X) and Taft21(Y).

Table 4. Displacement influence rate of SJ1 pier.

\begin{tabular}{cccccccccc}
\hline & \multicolumn{3}{c}{ EL-Centro } & \multicolumn{3}{c}{ Taft111 } & \multicolumn{3}{c}{ Taft111/Taft21 } \\
\hline PGA/g & 0.274 & 0.55 & 0.783 & 0.274 & 0.55 & 0.783 & 0.274 & 0.55 & 0.783 \\
\hline$i$ & 0.50 & 0.47 & 0.46 & 0.60 & 0.54 & 0.57 & 0.49 & 0.56 & 0.53 \\
\hline
\end{tabular}

Table 5. Displacement influence rate of SJ2 pier.

\begin{tabular}{cccccccccc}
\hline & \multicolumn{3}{c}{ EL-Centro } & & Taft111 & \multicolumn{3}{c}{ Taft111/Taft21 } \\
\hline PGA/g & 0.274 & 0.55 & 0.783 & 0.274 & 0.55 & 0.783 & 0.274 & 0.55 & 0.783 \\
\hline$i$ & 0.65 & 0.46 & 0.44 & 0.60 & 0.52 & 0.57 & 0.51 & 0.54 & 0.48 \\
\hline
\end{tabular}

It can be seen from Tables 4 and 5 that the displacement influence rates of the prefabricated SJ1 and SJ2 piers were similar. With the continuous increase of the PGA, the displacement influence rate always remained at about $50 \%$, the ductility of the pier is significantly improved, which proves that the steel jacket exerted a good limiting effect on the lateral displacement.

\subsection{Concrete Strain}

The concrete measurement points of the three piers were at the same location, and four strain measuring points were arranged at $90^{\circ}$ circumferential intervals on the concrete surface of the bottom of each pier. The development laws of the concrete strain of the three scaled piers under different earthquake conditions were recorded. A slight problem with the strain gauge collection was encountered, so the average value of the compressive strain measured by the four strain gauges under different loading conditions was taken as the final result of the concrete strain response. Furthermore, the concrete strains in the OpenSees model were extracted at $90^{\circ}$ circumferential intervals and averaged. Figure 9 exhibits the mean values of concrete compressive strain at the bottom of the pier under the action of the three types of seismic waves with the increase of the PGA, as well as the comparison with the finite element simulation results.

It can be seen from Figure 9 that as the PGA increased, the compressive strains of the three piers gradually increased. When the PGA was greater than $0.391 \mathrm{~g}$, the average compressive strain of the CIP pier increased with the decrease of stiffness. In contrast, the prefabricated piers benefitted from the restraint of the steel jacket on the concrete, so the average compressive strain of the piers increased linearly and steadily. The average values of the concrete compressive strain of the prefabricated piers were similar and much smaller than that of the CIP pier. This is because the concrete at the bottom of the two prefabricated 
piers was under three-way compression under the lateral restraint of the steel jacket, which reduced the average compressive strain of the concrete.

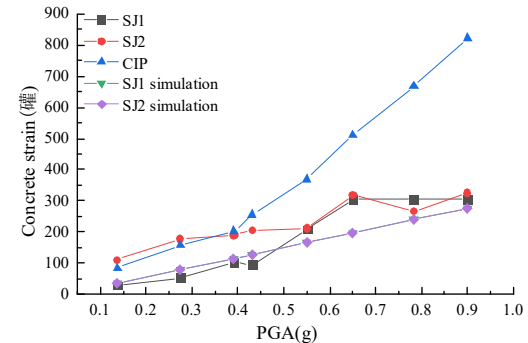

(a)

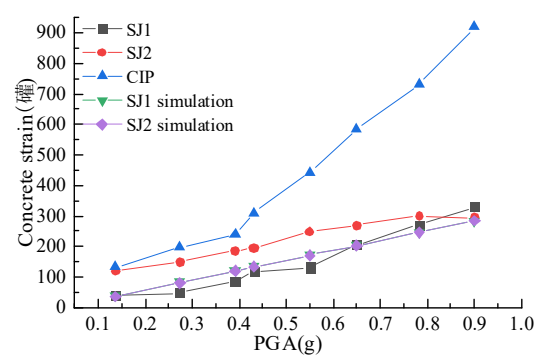

(b)

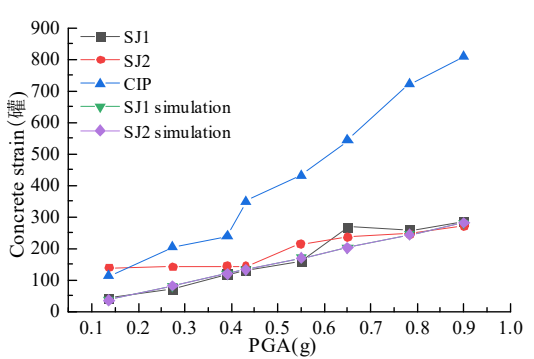

(c)

Figure 9. Concrete strain at pier bottom under different seismic wave: (a) El-Centro; (b) Taft111; (c) Taft111(X) and Taft21(Y).

\subsection{Reinforcement Strain}

With the continuous increase of the PGA, the reinforcement strain gauge loosened, leading to the decline section of some collected data. Therefore, the steel bar strain was considered as the mean value of the strain measured for the six steel bars. Moreover, the mean tensile strain of the six reinforcement fibers extracted from OpenSees was compared with the experimental data. Figure 10 presents the comparison between the mean tensile strain of the longitudinal reinforcement at the bottom of the three piers with the increase of the PGA under different seismic waves and the finite element calculation results. When the PGA was less than $0.55 \mathrm{~g}$, the longitudinal reinforcement tensile strains of the three piers all exhibited the tendency of gradually increasing. Under the same PGA, the mean tensile strains of the two prefabricated piers were less than that of the CIP pier, and that of pier SJ2 was slightly greater than that of pier SJ1; this indicates that the slightly shorter anchorage length of the reinforcement caused the reinforcement strain at the bottom of the upper pier to slightly increase. In the case of different bidirectional Taft seismic wave excitation, the longitudinal reinforcement strain of the pier bottom was greater than that under the same bidirectional seismic wave excitation; this was mainly due to the different degrees of bidirectional bending of the pier. The finite element calculation results exhibited a linear increase, which is consistent with the development trend of the reinforcement strain. The longitudinal strain of the CIP pier under the three seismic excitation modes was greater than that of the prefabricated piers, which proves that the prefabricated bridge pier exhibited good seismic performance.

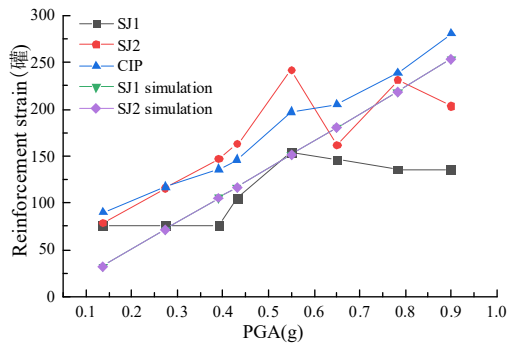

(a)

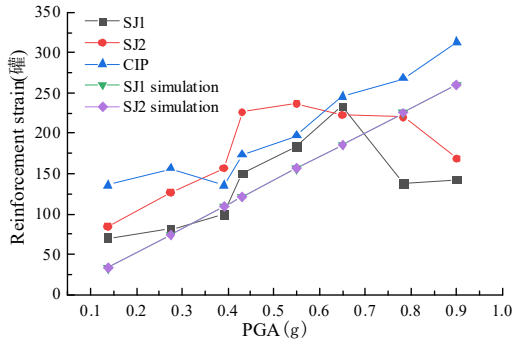

(b)

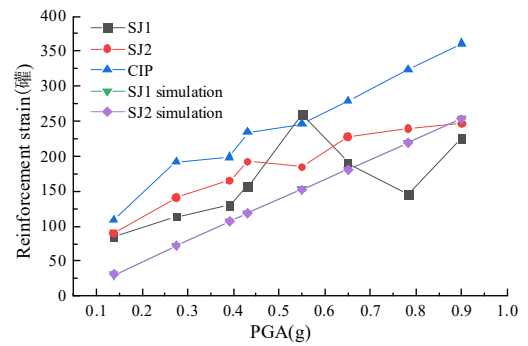

(c)

Figure 10. Concrete strain at pier bottom under different seismic wave: (a) El-Centro; (b) Taft111; (c) Taft111(X) and Taft21(Y).

\section{Discussion}

Based on the same group of experiments [25], in order to better improve the seismic performance of prefabricated single-segment concrete pier connected with the grouting sleeve, an external steel jacket was installed in the potential plastic hinge area at the bottom 
of the pier and the shaking table test was conducted on prefabricated pier with the steel jacket. Comparing the test data of the two structures, the pier with steel jacket exhibits higher stiffness, better ductility, smaller acceleration, displacement, and strain response, which proves that the installation of steel jacket can significantly improve the seismic performance of bridge piers. In practical engineering, the prefabricated pier with steel jacket can be more widely used in earthquake-prone areas.

\section{Analysis of Various Parameters of the Prefabricated Bridge Piers}

In the shaking table test and dynamic time-history response analysis, when the pier top counterweight was $400 \mathrm{~kg}$, the anchorage lengths of the steel bar were respectively 8 times and 10 times the steel bar diameter, and the steel jacket thickness was $2 \mathrm{~mm}$, the seismic performances of the prefabricated bridge piers were obviously superior to that of the CIP pier. Moreover, changing the anchorage length of the steel bar in the grouting sleeve was found to have almost no effect on the seismic performance of the prefabricated bridge piers, which proves that the experimental results were in good agreement with the simulation results obtained from the established finite element model. The influences of various design parameters on the seismic performance of the prefabricated piers were also investigated by using OpenSees.

\subsection{Influence of the Pier Top Counterweight on the Prefabricated Piers}

Under the action of bidirectional Taft seismic waves, the relationship between the maximum displacement angle of the pier top (the ratio of the difference between the displacement of the pier top and bottom and the pier height) and the pier top counterweight was obtained by gradually increasing the pier top counterweight under a certain PGA, as shown in Figure 11.

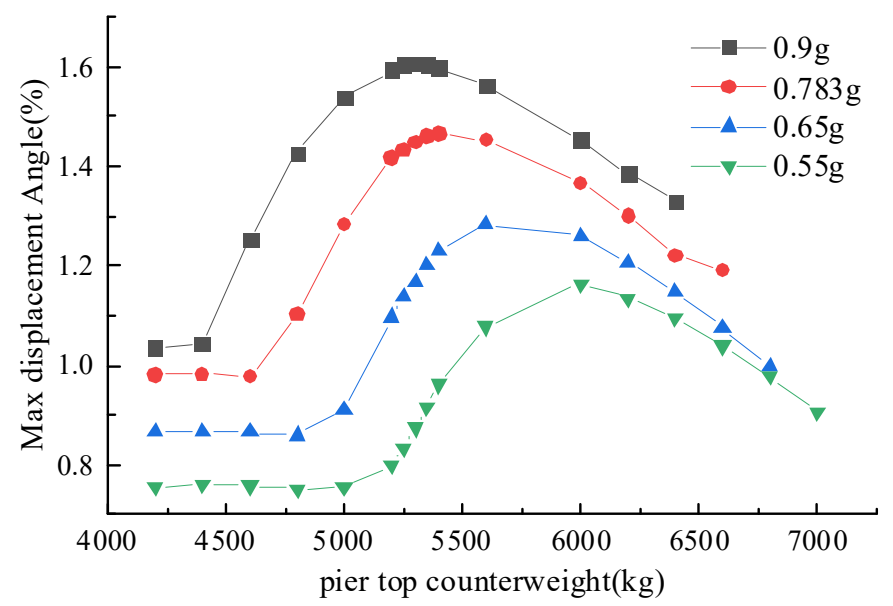

Figure 11. Maximum $X$-direction displacement Angle of pier top under different pier top counterweight.

Figure 11 reveals that when the PGA was $0.55,0.65,0.783$, and $0.9 \mathrm{~g}$, the maximum pier top displacement angle was generated when the pier top counterweight was 6000, 5600,5400 , and $5300 \mathrm{~kg}$, respectively. Thus, with the increase of the PGA, the maximum counterweight that the pier top could bear was found to gradually decrease. Furthermore, the maximum lateral force that the prefabricated pier can bear can be equivalent to the product of acceleration and the maximum pier top counterweight, i.e., with the increase of the PGA, the maximum lateral force that the prefabricated pier can bear also increases. The pier top weight was found to have a significant impact on the prefabricated pier, and the ultimate bearing capacity of the prefabricated pier was found to depend on both the PGA and the pier top weight.

Taking the pier top weight of $5300 \mathrm{~kg}$ and the PGA of $0.9 \mathrm{~g}$ under the action of Taft bidirectional seismic waves as an example, there was no strain value of the concrete in the OpenSees model at this time; this indicates that the concrete had been destroyed 
and crushed. Figure 12 presents the stress-strain curves of the steel bars at the bottom of the prefabricated pier in the X-direction. The hysteresis loop of the steel bars was found to be relatively full, which indicates that the steel bars could successfully dissipate seismic energy.

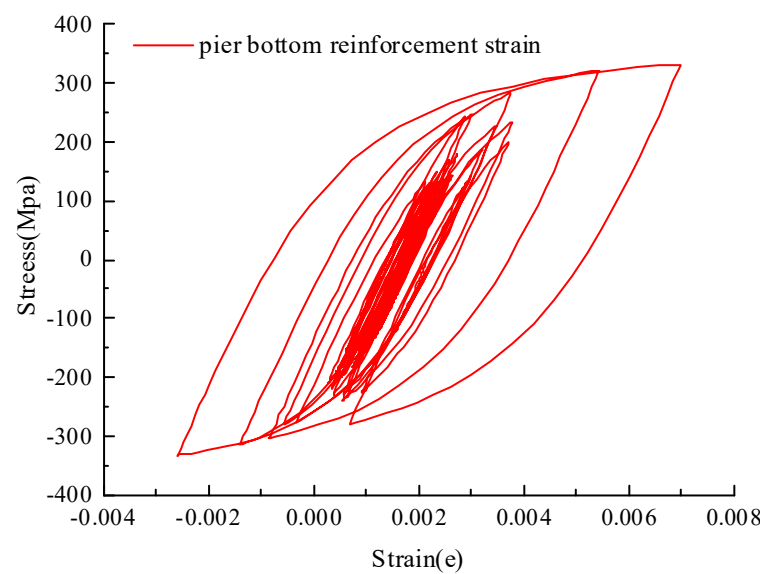

Figure 12. Stress-strain relationship of reinforcement under PGA $0.9 \mathrm{G}$ when pier top counterweight is $5300 \mathrm{~kg}$.

\subsection{The Influence of the Anchorage Length on the Prefabricated Bridge Piers}

As reported in Table 6, in combination with the experimental data obtained from the shaking table test and the finite element simulation results, the maximum $X$-direction relative peak displacement of the pier top was calculated and compared under the respective anchorage lengths of the grouting sleeve of $6,8,10,12$, and $14 \mathrm{~mm}$. The pier was considered to be under the action of Taft bidirectional seismic waves, the PGA was $0.9 \mathrm{~g}$, and the pier top counterweight was $400 \mathrm{~kg}$.

Table 6. Relative displacement peaks of pier top under different anchorage lengths when pier top counterweight is $400 \mathrm{~kg}$.

\begin{tabular}{cccccc}
\hline Anchorage Length & 6D & 8D & 10D & 12D & 14D \\
\hline relative peak displacement & 2.49095 & 2.48833 & 2.48569 & 2.48327 & 2.48084 \\
\hline
\end{tabular}

Figure 13 presents the $\mathrm{X}$-direction relative peak displacement of the pier top with the continued increase of its mass under different anchorage lengths.

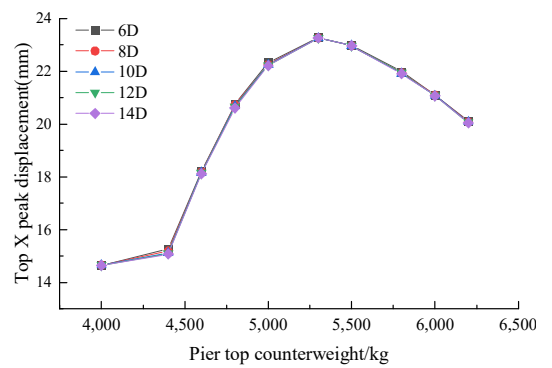

(a)

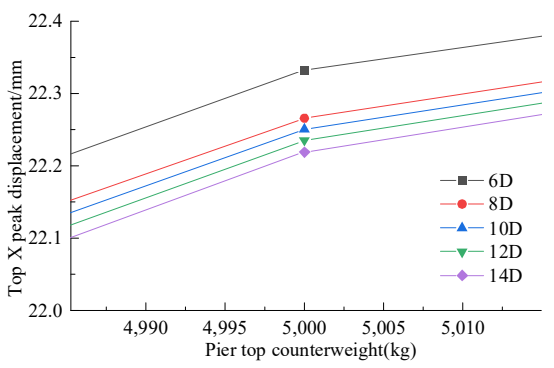

(b)

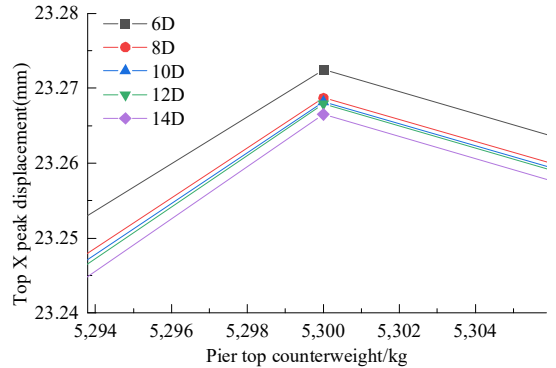

(c)

Figure 13. (a)The X-direction relative peak displacement of pier top under different anchorage lengths when PGA is $0.9 \mathrm{~g}$; (b) Local amplification when top counterweight is $5000 \mathrm{~kg}$; (c) Local amplification when top counterweight is $5300 \mathrm{~kg}$.

It can be concluded from Table 6 and Figure 13 that although the peak value of the $X$-direction relative displacement of the pier top was found to decrease with the increase of 
the anchorage length at the same pier top mass, the difference between different anchorage lengths was very small, and the change of displacement had almost no influence on the overall structure. Therefore, as long as the grouting is dense and the reinforcement in the sleeve is not pulled out, changing the anchorage length of the grouting sleeve within a certain range will have little influence on the seismic performance of the pier, and the anchorage length can be more than twice the minimum anchorage length stipulated in the current code requirements. Therefore, in the seismic design of prefabricated bridge piers connected with grouting sleeves, the anchorage length of the reinforcement can be varied within a certain range while satisfying the standard design and upper counterweight requirements.

\subsection{The Influence of the Thickness of the Steel Jacket}

The seismic response of the pier with different steel jacket thicknesses with the pier top counterweight of $400 \mathrm{~kg}$ was investigated. The SJ1 bridge pier model was considered, and the relative peak displacement value of the top of the pier in the X-direction under the action of the Taft bidirectional seismic wave was calculated under different steel jacket thicknesses, as exhibited in Figure 14.

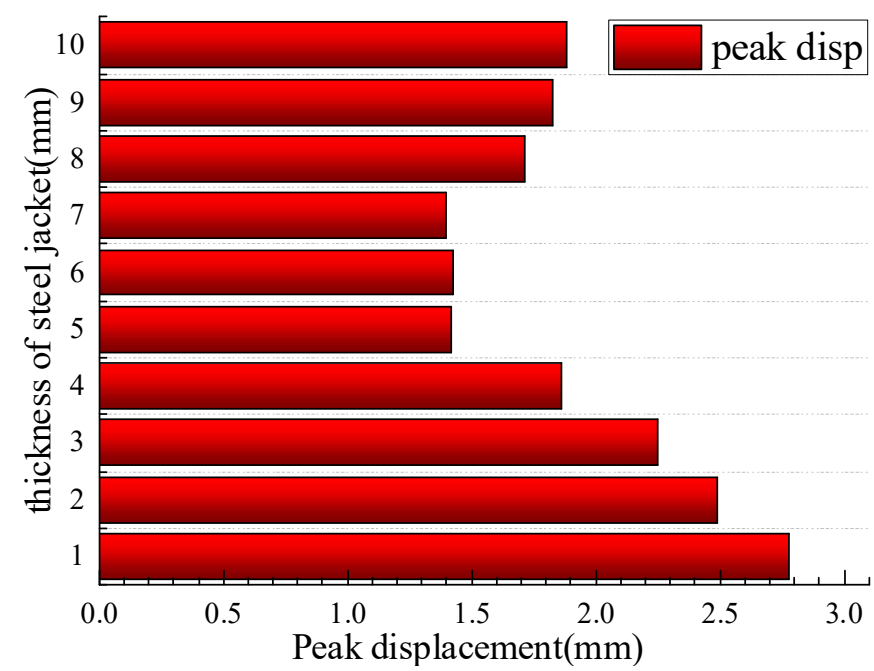

Figure 14. Relative peak displacement of pier top at different steel jacket thickness.

As can be seen from Figure 14, the constraint effect on the X-direction displacement of the pier top was the best when the thickness of the steel jacket was $5-7 \mathrm{~mm}$. If the steel jacket is too thin, it cannot play a good role in limiting the lateral displacement; conversely, if the steel jacket is too thick, the rigidity domain of the pier covered with the steel jacket will be too large. At this time, the rigidity of a pier not covered with a steel jacket will be far less than that of a pier covered with a steel jacket, and the vibration of the pier not covered with a steel jacket will be more intense under the action of ground vibration. Furthermore, the steel bar and the steel jacket were converted into concrete according to the equivalent area, and the equivalent stiffness of the cross-section of the steel jacket was obtained. It can be seen from Figure 15 that as the thickness of the steel jacket increased, the stiffness of the cross-section increased exponentially; thus, if the steel jacket is too thin or too thick, it will not produce a good displacement restraint effect. Therefore, for prefabricated single-segment steel jacket piers, the reasonable steel jacket thickness should be controlled within 5-7 $\mathrm{mm}$. 


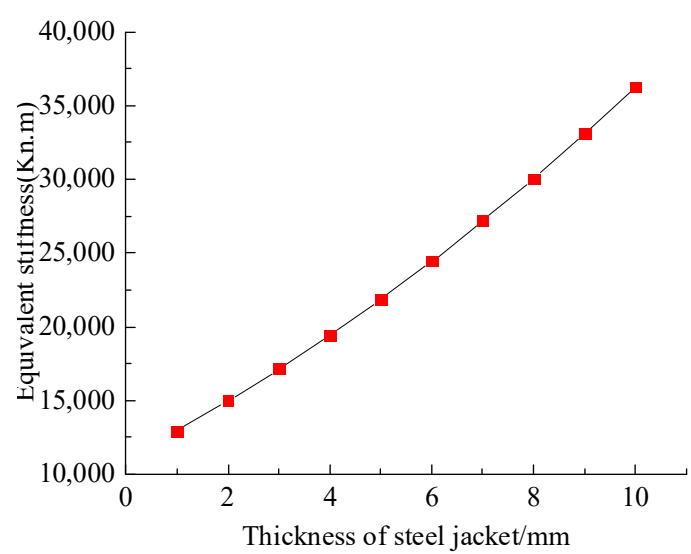

Figure 15. The relation between equivalent stiffness and thickness of steel jacket.

\section{Conclusions}

To study the seismic performance of prefabricated single-segment steel jacket bridge piers, two prefabricated single-segment steel jacket piers with different anchorage lengths of the reinforcement steel bars in the grouting sleeves were designed, and a comparison was made with a corresponding CIP pier. Shaking table tests and finite element simulations were carried out under different ground motion excitation intensities. The conclusions of this research are as follows.

(1) The natural frequencies of the two steel jacket prefabricated piers were greater than that of the CIP pier, and the steel jacket prefabricated piers had a higher stiffness than the CIP pier. The acceleration response, displacement response, strain response, and other seismic performance indicators of the two steel jacket prefabricated piers were less than those of the CIP pier; thus, the single-segment steel jacket prefabricated piers has better seismic performance than the CIP pier.

(2) The dynamic responses of the two prefabricated piers were similar under the same ground motion, indicating that the seismic performance of the prefabricated piers with steel jackets was not affected by changing the anchorage length of the reinforcement in the grouting sleeve. Moreover, the steel jacket has a good effect of increasing stiffness, decreasing strain, and limiting displacement. Therefore, the ductility of the pier is significantly improved. Compared with the same group of tests, the steel jacket prefabricated single-segment bridge pier connected by a grouting sleeve has better seismic performance.

(3) According to the OpenSees finite element parameter analysis, the pier top counterweight was found to have the greatest influence on the seismic performance of the prefabricated piers. With the increase of the PGA, the pier top counterweight that could be borne by the prefabricated piers was found to gradually decrease, and the maximum lateral resistance increased. Changing the anchorage length of the grouting sleeve within a certain range was found to have little effect on the seismic performance, and the anchorage length can be more than twice the minimum anchorage length specified in the current codes. Moreover, the thickness of the steel jacket should not be too thin or too thick, and the optimal thickness was found to be $5-7 \mathrm{~mm}$.

Author Contributions: Conceptualization, B.D., Y.J. and D.L.; formal analysis, analysis and writing, B.D.; writing and review, B.D. and Y.J.; methodology, B.D. All authors have read and agreed to the published version of the manuscript.

Funding: This study was supported by Natural Science Foundation of Heilongjiang Province of China (E2017003) and Scientific Research Project of Capital Engineering \& Research Incorporation Limited of China (01-20090230-286-304369).

Institutional Review Board Statement: Not applicable. 
Informed Consent Statement: Not applicable.

Data Availability Statement: Not applicable.

Conflicts of Interest: The authors declare no conflict of interest relevant to this work.

\section{References}

1. Tazarv, M.; Saiidi, M.S. UHPC-filled duct connections for accelerated bridge construction of RC columns in high seismic zones. Eng. Struct. 2015, 99, 413-422. [CrossRef]

2. Roh, H.; Reinhorn, A. Hysteretic behavior of precast segmental bridge piers with, superelastic shape memory alloy bars. Eng. Struct. 2010, 32, 3394-3403. [CrossRef]

3. Ameli, M.J.; Parks, J.E.; Brown, D.N.; Pantelides, C.P. Seismic evaluation of grouted splice sleeve connections for reinforced precast concrete column-to-cap beam joints in accelerated bridge construction. PCI J. 2015, 60, 80-103. [CrossRef]

4. Ou, Y.; Wang, P.; Tsai, M.; Chang, K.; Lee, G. Large-scale experimental study of precast segmental unbonded posttensioned concrete bridge columns for seismic regions. J. Struct. Eng. 2010, 136, 255-264. [CrossRef]

5. Parks, J.E.; Brown, D.N.; Ameli, M.J.; Pantelides, C.P. Seismic Repair of Severely Damaged Precast Reinforced Concrete Bridge Columns Connected with Grouted Splice Sleeves. ACI Struct. J. 2016, 113, 615-626. [CrossRef]

6. Tazarv, M.; Saiidi, M. Low-damage precast columns for accelerated bridge, construction in high seismic zones. J. Bridge Eng. 2016, 21, 13. [CrossRef]

7. Ameli, M.J.; Brown, D.N.; Parks, J.E.; Pantelides, C.P. Seismic Column-to-Footing Connections Using Grouted Splice Sleeves. ACI Struct. J. 2016, 113, 1021-1030. [CrossRef]

8. Burak, R.; Seraderian, R. Accelerated bridge construction-On the fast track to success. In Proceedings of the Annual Conference of the Transportation Association of Canada, Halifax, NS, Canada, 26-29 September 2010.

9. Wu, T.; Jiang, K. Experimental study on partially steel tube-confined RC column. Build. Struct. 2012, 42, 742-745.

10. Liu, Y.; Zhou, B.; Cai, J.; Lee, D.S.H.; Deng, X.; Feng, J. Experimental study on seismic behavior of precast concrete column with grouted sleeve connections considering ratios of longitudinal reinforcement and stirrups. Bull. Earthq. Eng. 2018, 16, 6077-6104. [CrossRef]

11. Deng, J.; Zong, Z. Anti-seismic properties of damaged concrete bridge piers with hollow cross-section strengthened with adhering steel plates II: Numerical analysis on seismic dynamic responses. J. Southeast Univ. (Nat. Sci. Ed.) 2013, 43, $1280-1287$.

12. Ding, M. Research on Seismic Retrofit Methods for Railway Bridge with Gravity Piers. Chin. J. Rock Mech. Eng. 2013, 43, 1280-1287.

13. Fan, P.P. Dynamic Performance Study of Strengthening Reinforced Concrete Column with Steel. Master's Thesis, Xi'an University of Science and Technology, Xi'an, China, 2008.

14. Huang, H.; Zhang, W. Comparison and analysis of seismic reinforcement methods for circular reinforced con-crete bridge piers. World Earthq. Eng. 2020, 36, 163-171.

15. Huang, H.; Zhang, W. Numerical analysis of seismic performance for circular RC bridge piers reinforced with circular steel tubes based on opensees. Earthq. Resist. Eng. Retrofit. 2020, 42, 113-120.

16. Wang, R.; Ma, B.; Chen, X. Seismic performance of pre-fabricated segmental bridge piers with grouted splice sleeve connec-tions. Eng. Struct. 2021, 229, 111668. [CrossRef]

17. Hewes, J.T. Seismic Design and Performance of Precast Concrete Segmental Bridge Columns. Ph.D. Thesis, University of California, San Diego, CA, USA, 2002.

18. Olmos, B.; Jara, J.M.; Gómez, G. Influence of steel jacket thickness on the RC bridges' seismic vulnerability. J. Traffic Transp. Eng. (Engl. Ed.) 2019, 6, 15-34. [CrossRef]

19. Dan, Z.A.; Ning, L.; Zxlab, C.; Lx, A. Rapid repair of rc bridge columns with prestressed stainless-steel hoops and stainless-steel jackets-Sciencedirect. J. Constr. Steel Res. 2020, 177, 106441.

20. Chou, C.; Chen, Y. Cyclic tests of post-tensioned precast CFT segmental bridge columns with unbonded strands. Earthq. Eng. Struct. Dyn. 2010, 35, 159-175. [CrossRef]

21. Ameli, M.J.; Pantelides, C.P. Seismic Analysis of Precast Concrete Bridge Columns Connected with Grouted Splice Sleeve Connectors. J. Struct. Eng. 2016, 143, 1-13. [CrossRef]

22. Zipeng, G.; Guangtao, X. Shaking table test study on grouting sleeve connecting assembled concrete pier. Earthq. Resist. Eng. Retrofit. 2020, 42, 84-90.

23. Apostolopoulos, C.; Drakakaki, A.; Basdeki, M. Seismic assessment of RC column under seismic loads. Int. J. Struct. Integr. 2019, 10, 41-54. [CrossRef]

24. Gu, S.K. Performance Analysis of Reinforced Concrete Hollow Pier Based on Dynamic Test. Master's Thesis, Hebei University of Engineering, Handan, China, 2018.

25. Xu, J.M.; Yan, M.J.; Liang, D.W. Shaking table test on single segment prefabricated concrete bridge pier connected by grouting sleeve. Int. J. Struct. Integr. 2021, 1757-9864. [CrossRef]

26. Zhang, M. Study on similitude laws for shaking table tests. Earthq. Eng. Eng. Dyn. 1997, 2, 52-58.

27. Ministry of Housing and Urban-Rural Development of the People's Republic of China. Technical Specification for Application of Steel Sleeve Grouting Connection(JTJ355-2015); China Architecture \& Building Press: Beijing, China, 2015. 
28. Ministry of Housing and Urban-Rural Development of the People's Republic of China. Code for Seismic Design of Buildings(GB50011-2010); China Architecture \& Building Press: Beijing, China, 2010.

29. Ministry of Housing and Urban-Rural Development of the People's Republic of China. Code for Seismic Design of Highways and Bridges (JTG/T2231-2020); China Architecture \& Building Press: Beijing, China, 2010.

30. Mander, J.; Priestley, M. Theoretical Stress-Strain Model for Confined Concrete. J. Struct. Eng. 1988, 114, 1804-1826. [CrossRef]

31. Scott, B.; Park, R.; Priestley, M. Stress-strain behavior of concrete confined by overlapping hoops at low and high strain rates. J. Proc. 1982, 79, $13-27$. 